\title{
Flexural Properties of Unidirectional Enset Fiber Reinforced Epoxy Composite for Automotive Interior Application
}

\author{
Abebayehu Abdela $^{1}$ Prof. Dr. ir. Mark Versteyhe ${ }^{2}$ Dr. Fasil Tadesse ${ }^{3}$ \\ 1.Ethiopia Institute of technology-Mekelle, P.O.Box 231, Mekelle, Ethiopia \\ 2.KU Leuven, Mechanical Engineering Technology Campus Bruges, Bruges, Belgium \\ 3.Ethiopia Institute of technology-Mekelle, P.O.Box 231, Ethiopia
}

\begin{abstract}
Natural fiber-reinforced composites have attracted the attention of the research community mainly because they are turning out to be an alternative solution to the ever depleting petroleum sources and have additional advantages emanating from their low cost, low density, renewability, recyclability and biodegradability over glass fiber. In this regard, Enset plant is a main staple crop in southern and central Ethiopia where the pulp is fermented for food production but its strong fibers are now only used for local rope making or they are discarded. This paper presents the characteristics of Enset fiber under flexural loading conditions. So, a fiber reinforced composite specimen with different standard span length, fiber age, and fiber volume fraction has been considered. The experiment has been designed and analyzed using Optimal Experiment Design and Taguchi array platform on JMP and Minitab software package. After density of the fiber is measured by a Gas Pycnometery, different range of flexural loading and different loading condition (intermittent and one time) using Instron machine has been applied and the result has been analyzed and interpreted accordingly. This work, finally, reports the flexural properties of the fiber to be: Density: $1.4 \mathrm{~g} / \mathrm{cm}^{3}$; Flexural strength at maximum load: 121.6Mpa-215.0Mpa, Mean strength at maximum load: 162.4; Mean strength at maximum extension: 96.47MP; Modulus: 8.081Gpa-12.02Gpa, Mean modulus: $10.903 \mathrm{MPa}$. Variation and standard deviation amid the results are minimal because of the bundle fiber sharing the load and reinforcing each other.
\end{abstract}

Keywords: Fiber, Enset, Processing, flexural

DOI: $10.7176 / \mathrm{CMR} / 11-8-02$

Publication date:October $31^{\text {st }} 2019$

\section{Introduction}

Natural fibers can be considered as composites of hollow cellulose fibrils held together by a lignin and hemicellulose matrix [1]. In this context, the cell wall in a fiber is not a homogenous membrane [2]. Each fiber has a complex, layered structure consisting of a thin primary wall which is the first layer deposited during cell growth encircling a secondary wall. The secondary wall is made up of three layers and the thick middle layer determines the mechanical properties of the fiber. The middle layer consists of a series of helically wound cellular micro-fibrils formed from long chain cellulose molecules. This structural configuration has its own impact on the characteristics of the fiber and their composite. Based on their response to different loading, different fibers have been used for different application. As a result, Fiber-reinforced composite materials want to be used in a large number of applications ranging from aerospace systems to automotive, industrial, and consumer products [3]. So far a good number of automotive components previously made with glass fiber composites are now being manufactured using environmentally friendly composites made up of bio-composites [20,21].

Interest in Natural Fiber composites is growing for many reasons including their potential to replace synthetic fiber reinforced plastics at lower cost with improved sustainability [9]. With this in mind, in recent years, the amount of research on natural fibers products has increased considerably [4]. Besides, sufficient recent findings favor natural fiber over synthetic ones for many reasons. For instance, natural fiber can be a relevant substitute of synthetic fibers since they are available naturally in a fiber form at low costs and they reach relatively high specific strength and rigidity owing to their low density [5]. Replacing of the synthetic fibers by the natural ones, thus, has a lot of benefits which can be rationalized also by means of an ecological equilibrium since natural fibers are ecofriendly while encompassing good properties compared to synthetic fibers. Other reason for this increase is due to a greater consciousness of the ever depleting trend of petroleum supplies [4]. Thus, Natural fibers have a big role to play towards a sustainable environmentally friendly future [4]. Besides, composite materials reinforced with natural fibers become more significant in constructional applications.

One of the suitable plants with great potential for the production of natural fibers with competitive properties is Ensete (Ensete ventricosum) also known as false banana [12]. An estimated 15-20 million people mostly in the SNNP, parts of Oromia and Gambela States support livelihoods as staple food with the pulp is fermented for food production but its strong fibers are now only used for local rope making or they are discarded. It is a perennial herbaceous plant that grows in Ethiopia and it is primarily intended for human consumption and animal feeding [13]. Over centuries the Ensete fibers have been extracted from the leaves of this plant as major material for the weaving, ropes and cord production, as well as for baskets production [14]. Composite material reinforced with 
Ensete fibers could be used for the production of parts for automotive industry. The aim of this experiment is to describe mechanical properties specifically flexural strength of the Enset composite.

Consequently, Enset farmers are not getting best out of the plant while industries are also missing the gain they ought to get from the fiber. Jointly, selling the fibers for manufacturing uses would be a win-win situation for both the industries and the farmers, and provide the latter with a much needed source of additional income because composite material reinforced with Ensete fibers can be used for diverse industrial application including the production of parts for automotive industry the existing enormous varieties of the plant in the country depending on different reasons including, agro ecological zones, soil type, environment may result in relatively different result. And, processing this agricultural products and making them input for industries would be important contribution to the development of agriculture, agro processing and industries. Thus, characterization of the fiber is required.

Natural fibers composites are now a day becomes a good supply for different parts; especially where light weight, and high specific strength are the major criteria. So far a good number of automotive components previously made with glass fiber composites are now being manufactured using environmentally friendly composites [15, 16]. Researchers [17, 18, and 19] already tried to establish characteristics of the fiber. The experiment to describe the effect of different determinant has been designed and relevant test has been made accordingly. Based on this method with optimal experimental design assisted by the JMP software package utilization as well as bundle test result reinforcement, Enset has been characterized.

\section{Materials \& methods}

\subsection{Enset fibers}

The fibers shown on figurel below were sourced out of Enset plant from, Kokosa wereda, West Asri zone Oromia, Ethiopia at 2628 meters above sea level with an annual average temperature of $21 \mathrm{LC}$ and an annual average precipitation of $2300 \mathrm{~mm}$ and a relative humidity of $81 \%$ according to the environmental authorities of the region.
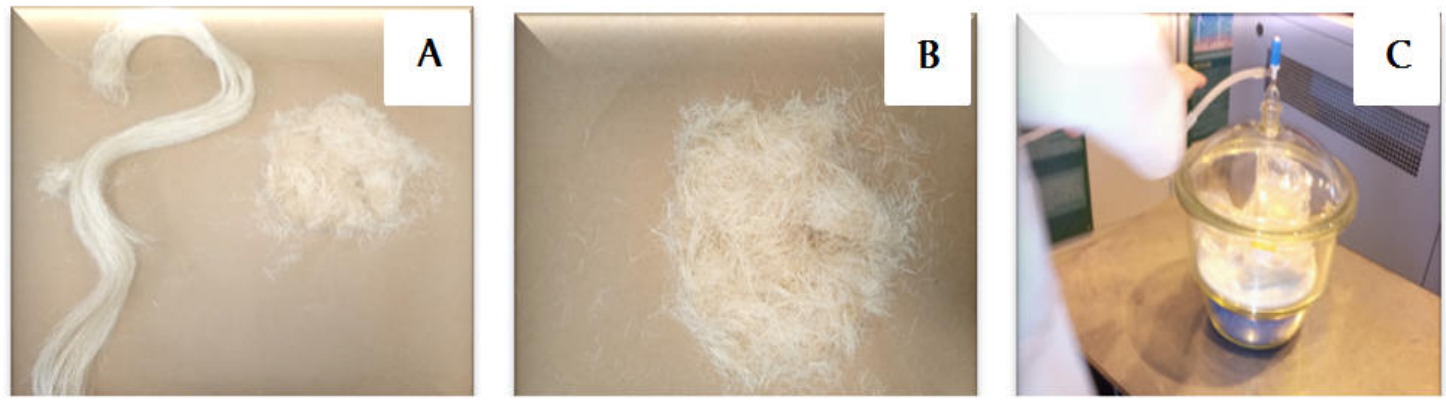

Fig 1: Enset fiber A) Fiber for unidirectional test B) Fiber prepared for density test and C) fiber in the desiccator

For this research, manually extracted Enset fibers using an in house developed technique meant only for extracting the pulp are considered. Long fiber displayed on figure $1 A$ has been made ready to study unidirectional fiber characteristic under flexural loading in its composite; figure $1 B$ shows fiber cut to $1 \mathrm{~mm}$ length for density measurement and figure $1 C$ fiber put inside the desiccator for drying or removing moisture. The density of the fibers was determined using a gas Pycnometery, Beckman model 930, in which helium gas at a pressure of 0.5 bar was used as the displacement medium. For density measurement, the fibers were cut to a length of $1 \mathrm{~cm}$ and vacuum dried for $24 \mathrm{hr}$ at $60 \mathrm{LC}$ [18]. The mass of these fibers, to determine the density, is measured using sensitive balance with accuracy to $10^{-5} \mathrm{~g}$. The measured density was $1.4 \pm 0.03 \mathrm{~g} / \mathrm{cm}^{3}$. The fibers were dried for $24 \mathrm{hr}$ at $60 \mathrm{LC}$ and subsequently conditioned at 50\% relative humidity (RH) and $21 \mathrm{LC}$ for $24 \mathrm{hr}$. In the latter condition, the fiber cut to specific length has been measured with sensitive balance of $10^{-5} \mathrm{~g}$ accuracy. The fiber is then impregnated in to epoxy resin and then molded in to a mold with $10 * 2 \mathrm{~mm}$ cross-sectional area and different length $(20 \mathrm{~cm}, 25 \mathrm{~cm}$, and $30 \mathrm{~cm}$ ) of fiber, to suit different span length during measurement, has been prepared. The fiber used for bundle test also dried for $48 \mathrm{hr}$ at $60 \mathrm{LC}$ and subsequently conditioned at $50 \%$ relative humidity (RH) and $21 \mathrm{LC}$. Three volume fractions $(35 \%, 40 \%$ and $45 \%)$ have been considered and the following equation is used to determine the mass of fiber, volume of fiber, resin and hardener mass required.

In the above equation

$$
F V F=\frac{1}{1+\frac{\dot{\rho} f}{\dot{\rho} m}\left(\frac{1}{f v f}-1\right)}
$$

$\boldsymbol{F} \boldsymbol{V} \boldsymbol{F}$ is fiber volume fraction,

$\dot{\boldsymbol{\rho}}_{f}$ is the fiber density and

$\dot{\boldsymbol{\rho}}_{\boldsymbol{m}}$ is the matrix density. 


\subsection{Experimental Design}

To get illustrative results of the impregnated fiber tests, the experiments have been designed and the factors affecting the result are included in the design. While including the factors main effects and 2-level interaction effects of the parameters have been considered. A software package from SAS (JMP pro 13) has been used to design the experiment described above. The DOE platforms and Taguchi array of the same software helped to design and analyze experiments. These parameters include volume fraction, Age, gauge length, treatment time, and Compression beginning temperature.

\subsection{Bundle Test Setup}

\subsubsection{Mold and Specimen Preparation}

The standard mold used to prepare specimens based on the fiber volume fractions (FVF) is a rectangular prism with internal dimension and/or volume of $\left(2 * 10 * 25=500 \mathrm{~mm}^{3}\right),\left(2 * 10 * 20=400 \mathrm{~mm}^{3}\right),\left(2 * 10 * 15=300 \mathrm{~mm}^{3}\right)$. The thickness measurement ranges from $1.8 \mathrm{~mm}$ to $2.36 \mathrm{~mm}$ wjile the width measurement ranges from $9.7 \mathrm{~mm}$ to $10.46 \mathrm{~mm}$ though the expected actual thickness and width of of the specimen is expected to be $2 \mathrm{~mm}$ and $10 \mathrm{~mm}$ respectively. $2 \mathrm{~mm}$ thick aluminum spacers are used at two ends inside the mold to generate uniformly distributed $2 \mathrm{~mm}$ thickness up on completion of the specimen's preparation. The length of samples are partially made long and cut in to piece. The volume fraction is also taken from this prism volume and interpreted in terms of mass by using the relationship between density, mass and volume given on equation 2 below.

$$
\dot{\rho}=\frac{m}{v}(e q .2)
$$

The minimum number of specimen required based on the design using the optimal design of experiment is prepared using the aforesaid mold. Mass fraction is derived from the volume fractions used using equation 1. In the process of developing the specimen, Aceton and release agents are used to clean the molds part and allow simple de-molding after compression molding and hot pressing respectively. The fiber is then impregnated in to the resin (Epoktet 828 LVEL) proportion gained via calculation using equation 1 and mixed with $15.2 \%$ hardener (Dytek DCH-99). After mixing the hardener with the resin, vacuum degassing is used. Then, the impregnated fiber is located on the plastic cover and pressed in to the mold manually to make it ready for hot pressing. The process of compression molding is then used to prepare specimens to study the composite unidirectional characteristics under flexural loading. The specimen made is pressed at a temperature of $70^{\circ} \mathrm{C}$ for 1 hour and then $150^{\circ} \mathrm{C}$ for additional 1 hour. High temperature resistant foam has been used to allow uniform load distribution across every specimen. Up on completion of the 2 hours, the mold was removed and air cooled. Then, de-molding has been done and the specimen is treated at $60^{\circ} \mathrm{C}$ for 24 hour to attain uniformity and required result. Then, the specimen is made ready for test as it is partly displayed on the figure 2 below.

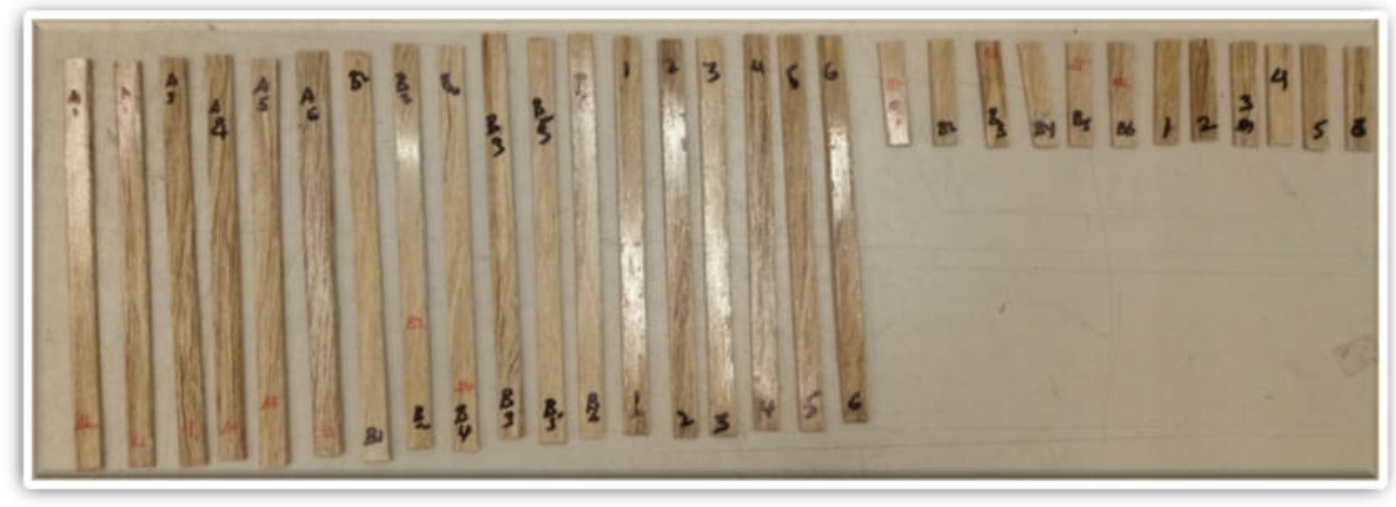

\subsubsection{Composite Flexural strength}

Figure 2: Specimen produced using compression molding and ready for tensile test

An ASTM test standard with D 7264/D 7264M - 07 designations is utilized to perform flexural test and characterization of composite specimens stated above. The machine on which the test was conducted is Instron 5567 with $1 \mathrm{KN}$ and $30 \mathrm{KN}$ load cell is used to check the effect of intermittent loading and maximum load caring capacity respectively. Series of tests have been accomplished on the aforesaid samples using the data capturing Bluehill software application working in integration with Instron 5567, testing machine. The rate of expansion used in this test is $1 \mathrm{~mm} / \mathrm{min}$. The flexural stress at maximum load, the flexural stress at maximum extension, the modulus and the strain at failure has been deployed from the experiment result and analyzed. When a beam of homogenous, elastic material is tested in flexure as a beam simply supported at two points and loaded at the midpoint, the maximum stress at the outer surface occurs at mid-span, which is technically termed as three point bending [22]. The stress is calculated for any point on the load-deflection curve by the following equation. 
Where

$$
\sigma=\frac{3 P L}{2 b h^{2}}(e q u .3)
$$

$\boldsymbol{F S}$ is stress at the outer surface at mid span in $\mathbf{M P a}$,

$\boldsymbol{P}$ Applied load in $\boldsymbol{N}$,

$\boldsymbol{L}$ is support span in $\boldsymbol{m} \boldsymbol{m}$;

$\boldsymbol{b}$ is width of beam in $\boldsymbol{m} \boldsymbol{m}$ and

$\boldsymbol{h}$ thickness of the beam in $\boldsymbol{m} \boldsymbol{m}$.

And, the flexural strength equals the maximum stress at the outer surface corresponding to the peak applied force prior to failure. Similarly, the maximum strain at the outer surface also occurs at the mid-span, and it is being calculated using the following equation.

Where the

$$
\dot{\varepsilon}=\frac{6 \delta h}{L^{2}}(e q u .4)
$$

$\dot{\varepsilon}$ is maximum stress at the outer surface in $\mathbf{m m} / \mathbf{m m}$;

$\boldsymbol{\delta}$ is mid span deflection in $\boldsymbol{m} \boldsymbol{m}$;

$\boldsymbol{L}$ is support span in $\boldsymbol{m} \boldsymbol{m}$,

$\boldsymbol{h}$ is thickness of the beam in $\boldsymbol{m m}$.

\section{Result and discussion}

The experiments are designed using JMP 13 pro; $D O E$ custom design platform jointly with Taguchi Array to get the optimal design result. The analysis platform on the same software in conjunction with Excel programming and Minitab software is used. Then, minimum number of experiments recommended by the software has been made with additional experiments, for boosting the certainty of the result. These experiments are conducted with representative repetition of runs or experiments. The flexural strength and associated characteristics of Enset fiber is described here below on Fig 3.
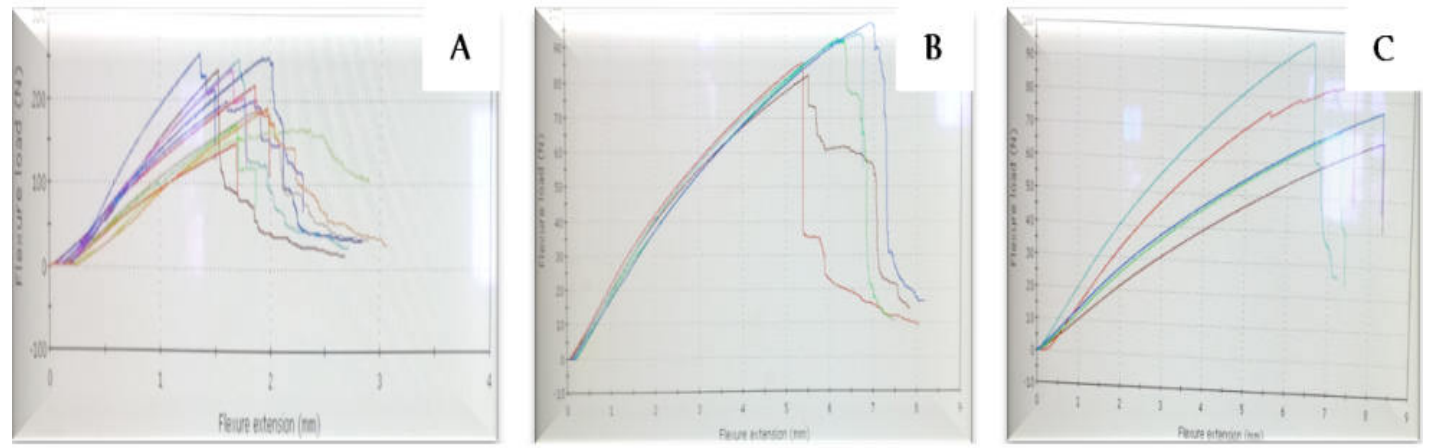

Fig 3: Flexural loading and response characteristics A) 2.5 years, B) 2 Years C) 1.5 years

As it is evident from the above graphs, the fiber with 2.5 years old exhibits better flexural strength related properties than the other two (1.5 and 2 years old). Plus, the difference between the results of the categories mean flexural stress at maximum load is not that big and the standard deviation visualized in the measurements is small. Graph 4 below clearly shows the difference between maximum flexural strength and minimum flexural strength during the test is small enough and the standard deviation equals $22.81 \mathrm{Mpa}, 14.76 \mathrm{Mpa}, 13.43 \mathrm{Mpa}$ for maximum loads for three cases $215,00731 \mathrm{Mpa} 150,36334 \mathrm{Mpa}, 161,13838$ respectively. This is not the case in the later condition (Fig 4B) where the criterion considered is maximum extension. Similarly, the average values for all the cases are nearly equal indicating the property difference based on age is small. The standard deviation between the average values is $1.28525 \mathrm{Mpa}$ which is less than $8 \%$ of the mea flexural strength at maximum load as it is mentioned here above. Figure 5 below summarizes the aforesaid result associated characteristics. 

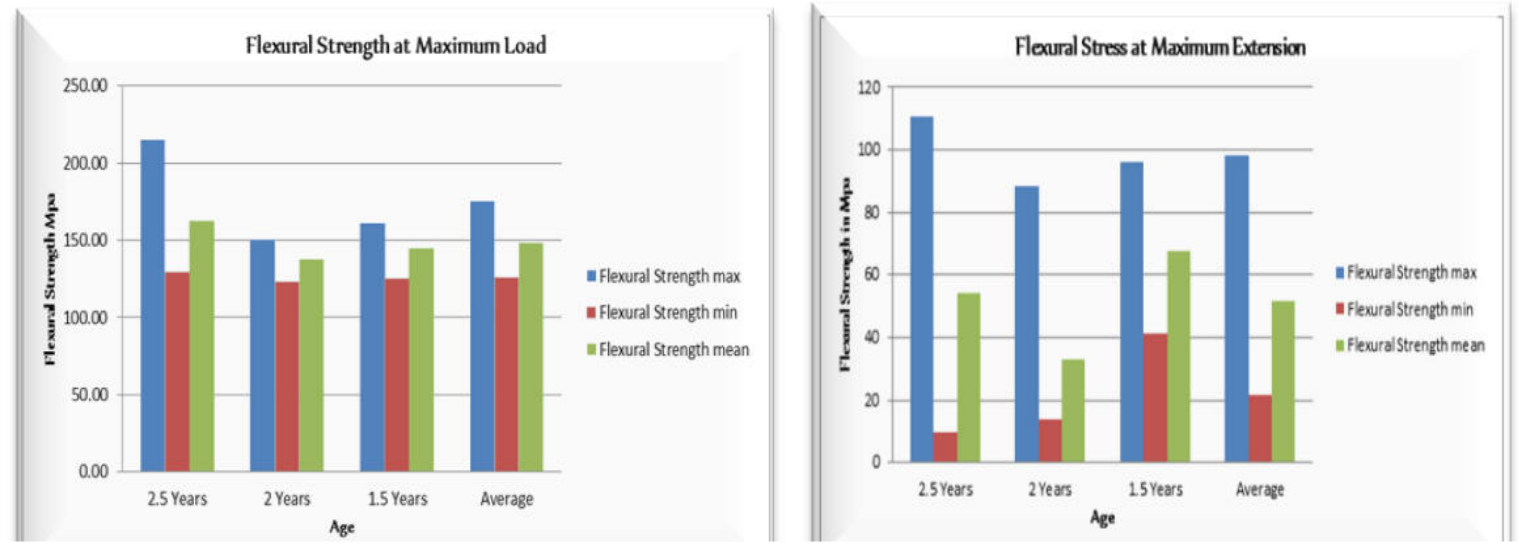

Fig 5: Maximum flexural strength A) At maximum Load B) At maximum Extension

The graph shows that the flexural strength at of maximum load is found for $35 \%$ fiber volume fraction and the maximum flexural strength at this volume fraction for fiber with 2.5 years of age and its value became 215.0Mpa while the minimum value for the same fiber was found to be $129.6 \mathrm{Mpa}$ with the mean being $162.4 \mathrm{Mpa}$. The same way the strength of the material characterized here above, the modulus in flexural loading has been pigeonholed on Fig 4 as below.

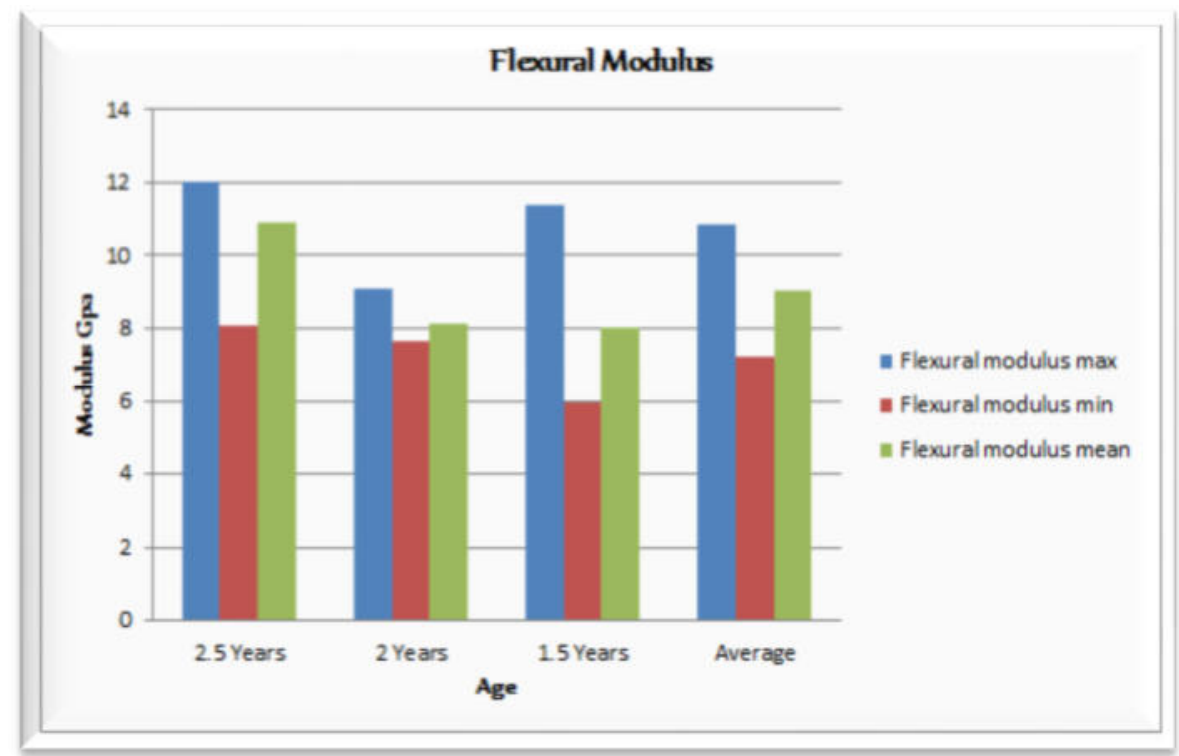

Figure 4: Modulus under flexural loading

Here above, the standard deviation between the results, which $8 \%$ or less, of the maximum value resulted from the nature of the bundle test where the failure the damaged fiber is mitigated by the non-damaged one. But still the smaller difference might have resulted from the fiber damage resulted from mechanical extraction leading to premature failure and fiber inside the fiber which not proportion jointly with the fiber diameter inconsistence across the length of the fiber. And very negligible amount of the difference reason emanates from the pre-load introduced during the test which is actually prohibited not to exceed $0.005 \mathrm{~N}$ during the experiment. The maximum value for the Modulus is $11.363 \mathrm{Gpa}$ and the minimum value is $5.933 \mathrm{Gpa}$ as it is displayed here above. This entails the tendency of this composite to resist bending. This value exceeds the expectation of material properties for automotive interior requirement. The flexural strength required requirement for automotive interior can be satisfied by the properties of Enset fiber reinforced composite material. For instance, polypropylene is one of the material used for automotive interior has a flexural strength of $40 \mathrm{Mpa}$ and $2.5 \mathrm{Gpa}$ which is less than the performance of Enset. Enset fiber reinforced composite exceeds the flexural strength of polystyrene which has 70Mpa and 2.5Gpa Flexural strength and flexural modulus. One can also consider plastic PVC one of the materials possibly used for automotive interior with different modification can achieve maximum flexural strength of about 114Mpa which is still less than the performance of the Enset fiber reinforced epoxy composite. And, chemical treatment can even enhance the properties more than this value. 
On the other hand the effect of loading a specimen with smaller load $1 \mathrm{KN}$ and seeing the effect, it had been visualized that the specimens doesn't fail. However, when the specimen is loaded with $30 \mathrm{KN}$ load to see the failure characteristics of the, is exhibits odd pattern and fails before the normal failure point showing the reduction of the flexural strength. This emanates from the prior loading resulted de-bonding. This is important because the application expected is for automotive interior application where small loads are continuously applied and there will be maximum loading only during crash. However, the strength even after this loading exceeds the expected load for the aforementioned application. And finally the stress strain curve can be summarized as follows.

\section{Conclusion}

This paper characterized successfully the flexural strength related properties of Enset fiber which is a suitable candidate material for natural fiber reinforced composites that can be used as automotive interior, specially car dashboard. The characteristics were determined on a bundle of fiber in a composite structure. In characterizing the properties Enset fiber composite, the paper dealt with the identification of optimum Faber volume fraction for best performance in flexural loading and found the 2.5 years maturity and $35 \%$ fiber volume fraction. The use of designing the experiment using optimal experimental design has made the number of the experiment to be known which has significant impact on the outcome in terms of its representativeness. The experiments revealed adequate strength of the fiber in line with other fibers already used to reinforce composites and other petrochemical currently used for automotive dashboard production. The moisture susceptibility of the fiber in a composite matrix could be mitigated using treatments and surface developments including alkali treatment, Silane treatment, and the combined effect of alkali and Silane treatments. Finally, the result of the test and the analysis indicated that Enset fiber can be used for automotive dashboard and other interior part development as well as different industrial application including airplane interior and related non-load bearing parts.

\section{References}

[1] K. Jayaraman, Compos. Sci. Technol., 63, 367 (2003).

[2] M.Z. Rong, M.Q. Zhang, Y. Liu, G.C. Yang, and H.M. Zeng, Compos. Sci. Technol., 61, 1437 (2001).

[3] Katharina Albrecht et.al, 2018, Length Reduction in Natural Fibre-Reinforced Polymers during Compounding and Injection Moulding-Experiments Versus Numerical Prediction of Fibre Breakage, Journal of Composites Science, 2018

[4] Haag K, Mussig J. Scatter in tensile properties of flax fiber bundles: influence of determination and calculation of the cross-sectional area. J Mater Sci 2016

[5] ASTM C1557-14. Standard test method for tensile strength and young's modulus of fibers. In: ASTM international, West Conshohocken, PA., www. astm.org.

[6] Alves et al., 2010, Eco-design of automotive components making use of natural jute fiber composites, Sciences direct, 2010

[7] Delphine Depuydt et al., 2017, Digital image correlation as a strain measurement technique for fibre tensile tests, Elseveir, 2017

[8] Shah DU, Nag RK, Clifford MJ. Why do we observe significant differences between measured and 'backcalculated' properties of natural fibers? Cellulose 2016.

[9] Mohanty AK, Khan MA, Sahoo S, Hinrichsen G. Effect of chemical modification on the performance of biodegradable jute yarn-Biopol (R) composites. J Mater Sci 2000;35(10):2589-95.

[10] Larbig H, Scherzer H, Dahlke B, Poltrock R. Natural fibre reinforced foams based on renewable resources for automotive interior applications. Journal of Cellular Plastics 1998;34(July/August):361-79.

[11] Leao A, Rowell R, Tavares N. Applications of natural fibres in automotive industry in Brazil thermoforming process. In: $4^{\text {th }}$ International conference on frontiers of polymers and advanced materials conference proceedings. Cairo, Egypt: Plenum press;1997. p. 755-60.

[12] Tsehaye, Y. \& Kebebew, F. 2006. Diversity and cultural use of Enset (Enset ventricosum (Welw.) Cheesman) in Bonga in situ Conservation Site, Ethiopia. Ethnobotany Research and Applications 4, 147-57.

[13] Vincent, H., Wiersama, J., Kell, S., Fielder, H., Dobbie, S., Castaneda-Alvarez, N.P., Guarino, L., Eastwood, R., Leon, B. \& Maxted, N. 2013. A prioritized crop wild relative inventory to help underpin global food security. Biological Conservation 167, 265-275.

[14] Diriba, H.D., Mazancová, J., Rušarová, K. \& Havrland, B. 2013. Possibilities and Acceptance of Alternative Energies from Farm Solid Waste Material (Kocho): Case Study from Kembata Tenbaro Zone. EthiopiaTropentag 2013 International Research on Food Security, Natural Resource Management and Rural Development Agricultural development within the rural urban continuum, Gottingen.

[15] Shah DU, Nag RK, Clifford MJ. Why do we observe significant differences between measured and 'backcalculated' properties of natural fibers? Cellulose 2016.

[16] Sharifah \& Martin, 2004, Review: finite element analysis of stress transfer in short-fibre composite materials, Composites Science and Technology, 2004 
[17] Dunne, R. Desai, D., Sadiku, R., Jayaramudu, J, 2016, A review of natural fibres, their sustainability and automotive applications Journal of Reinforced Plastics and Composites, 2016

[18] Haag K, Mussig J. Scatter in tensile properties of flax fiber bundles: influence of determination and calculation of the cross-sectional area. J Mater Sci 2016

[19] Kim JH, Heckert NA, Mates SP, Seppala JE, McDonough WG, Davis CS, et al. Effect of fiber gripping method on the single fiber tensile test: II. Comparison of fiber gripping materials and loading rates. J Mater Sci, 2015

[20] Larbig H, Scherzer H, Dahlke B, Poltrock R. Natural fibre reinforced foams based on renewable resources for automotive interior applications. Journal of Cellular Plastics 1998; 34 (July/August):361-79.

[21] Leao A, Rowell R, Tavares N. Applications of natural fibres in automotive industry in Brazil-thermoforming process. In: $4^{\text {th }}$ International conference on frontiers of polymers and advanced materials conference proceedings. Cairo, Egypt: Plenum press; 1997. p. 755-60.

[22] ASTM Designation D 7264/D 7264M - 07, Standard Test Method for Flexural Properties of Polymer Matrix Composite Materials, 